\title{
A Study on Evaluation and Optimization of Gel Flooding in Liaohe Oil Field
}

\author{
Matamba Musungayi Georges*, Pang Zanxi, Kamgue Lenwoue Arnaud Regis, Marembo Michael \\ College of Petroleum Engineering, China University of Petroleum, Beijing, China \\ Email address: \\ Georges.matamba@yahoo.com(M. M. Georges),pxiad9827@163.com (PangZanxi),2017392003@student.cup.edu.cn(K.L.A. Regis), \\ marembomicheal@yahoo.com(M. Michael) \\ ${ }^{*}$ Corresponding author
}

\section{To cite this article:}

Matamba Musungayi Georges, Pang Zanxi, Kamgue Lenwoue Arnaud Regis, Marembo Michael. A Study on Evaluation and Optimization of Gel Flooding in Liaohe Oil Field. International Journal of Engineering Management. Vol. 3, No. 1, 2019, pp. 25-32. doi: $10.11648 /$ j.ijem.20190301.15

Received: June 9, 2019; Accepted: July 8, 2019; Published: July 31, 2019

\begin{abstract}
There are many challenges during water injection such as the early breakthrough of injecting water, increasing of water production, and the rapid decline of oil rate. These problems are often faced during water flooding application, and many oil field around the world are experiencing these kinds of problems. Liaohe oil field, is not spared of this problem related to the excessive production of water. Therefore, due to this circumstance, conformance treatment has been applied to solve this problem in that oil field. Gel treatment is one of the viable solution to mitigate sweep conformance problems, decrease the excessive production of water and improve oil recovery. Before, gel treatment in Liaohe oil field especially in Hai1 block, laboratory study under field conditions was carried out to determine the chemical parameters of the gel injection. Thus, we also brought a simulation approach in this research. Therefore, a brief study on gel flooding treatment has been presented and investigated in Hai 1 block of Liaohe oil field in this paper. Three well patterns such as five point, seven point and nine point, were developed for water flooding and gel flooding. Step by step for each scenario, based on the reservoir parameters and fluid properties of the actual oil field, the injection rate and the liquid production rate have been optimized including well pattern. The results of the simulation showed that seven spot is the best well pattern and it is suitable for the model established in this research. In addition, after two years of gel injection, the excessive production of water decreases from 98 to $84 \%$ and the ultimate oil recovery increases up to $34 \%$ for gel flooding compare to $28 \%$ obtained during water flooding.
\end{abstract}

Keywords: Water Flooding, Gel Flooding, Optimization, Oil Recovery, Water Cut

\section{Introduction}

During water flooding, the fluids injected into oil reservoirs always flow easily and fast through higher permeability zone, which would cause low sweep efficiency and high remaining oil saturation. Conformance control is a necessary method to solve this kind of problem. Thus gel treatment is designed: (a) To plug higher permeability zone, and (b) To increase sweep efficiency then obtain higher oil recovery and lower water production. Gel treatment has been proved as a cost-efficiency conformance control method. It is a chemical EOR method which is often applied to improve injection profile. In general, there are two major gel treatment systems: in-situ gel system and preformed gel system. In several field applications, polymer solutions are mixed with cross-linking agents to form an in-situ polymer gel that can be used to treat common reservoir conformance problems [1].Different from in-situ gel, PPG is formed and cross linked at surface facilities rather than in formation after injection. Therefore, the gelation can be controlled.

Generally, the heterogeneity of reservoir depends on the depositional environment and subsequent events. The important thing to be understood is that there are no homogenous reservoirs, only varying degree of heterogeneity exists worldwide [2]. Reservoir heterogeneity can broadly be classified into three classes-microscopic heterogeneity that is characterized at pore scale; macroscopic heterogeneity that is represented at well or intra formation scale and; megascopic heterogeneity which is at field wide or regional levels [3]. 
The degree of reservoir heterogeneity is used to characterize a formation and predict the performance of a reservoir [4].

Several studies on water application and gel flooding treatment have been conducted and reported in order to understand the mechanism of these two methods for conventional heavy oil reservoir. T. Khamees, R. E. Flori, and M. Wei, conducted a comprehensive study of deep placement of weak gel in thick heterogeneous reservoir, and demonstrated that injecting even a low PV gel into gel high permeability layers could make a remarkable increase in oil recovery factor and incremental oil over the base case water flooding [5]. There are many challenges during water injection because of high increasing rate of water cut. Yanlai Li, Yanchun Su, Kuiqian Ma, Qizheng Li, Xiaofei Jia, also conducted a simulation for understanding the gelation process in the reservoir for LD oil field after a long term of gel flooding and demonstrated the effectiveness of gel flooding in that oil field, the results from simulation showed how water cut decreased after gel treatment [6].

So, numerical simulation is commonly used to build reliable reservoir models and understand the concept of gel flooding.

The interest of this paper is mainly based on gel flooding treatment in an actual oil field. In other term, the paper concerns the evaluation and optimization of gel flooding in hai 1 block of Liaohe oil field. A consideration on well pattern analysis, injection intensity, injection rate and optimization of liquid production rate for water flooding, and injection parameters for gel flooding has been presented to study the improvement of oil recovery in Liaohe oil field. A comparison between water flooding and gel flooding before and after optimization have been discussed.

\section{Numerical Simulation}

\subsection{Research Work Flow}

According to the reservoir parameters and fluid properties, numerical simulation is used to optimize well pattern, water injection rate and liquid production rate for the actual oilfield (Hai 1 block).In order to choose the best well pattern, three well patterns, such as five point, seven point and nine point are designed for the oilfield. Based on the formation factor, $\mathrm{KH}$, of each production well, we get the production rate of each well according to the balance of injection and production. Then a parameter, the injection intensity (the ratio of water injection rate and net pay of each injection well), is used to optimize water injection rate for each injection well on the basis of the optimum well pattern. Finally, a new parameter has been introduced to design liquid production of each production well in order to optimize liquid production rate of production well in the actual oilfield. Due to serious water channeling between injection wells and production wells, an EOR method, gel flooding, is employed to decrease water mobility in channeling path and increase sweep efficiency of injection liquids after water flooding. Numerical simulation is utilized to optimize injection-production parameters of gel flooding for the field, which includes gel concentration, injection rate, and injection time. Therefore, the optimum development strategy can be supply from the stage of water flooding to the stage of gel flooding for the actual oilfield.

\subsection{Model Description}

Liaohe oil field contains many blocks, Hail block has been used to achieve this research. Due to a serious production of water observed in Hail block during water flooding application. Gel flooding was applied in order to reduce the excessive production of water and improve the oil production.

The reservoir model established in this study, used the information of the structure of Hail and fluids properties of the field. The model is created to be 60,40 and 17 grids blocks in I, $\mathrm{J}$ and $\mathrm{K}$ directions in STARS and the simulation period is ranged from 1999 to 2022 (i.e. 33 years). STARS Simulator is developed by CMG (Computer Modeling Group LTD). It has many simulation options such as water flooding, chemical flooding, thermal application and other options.

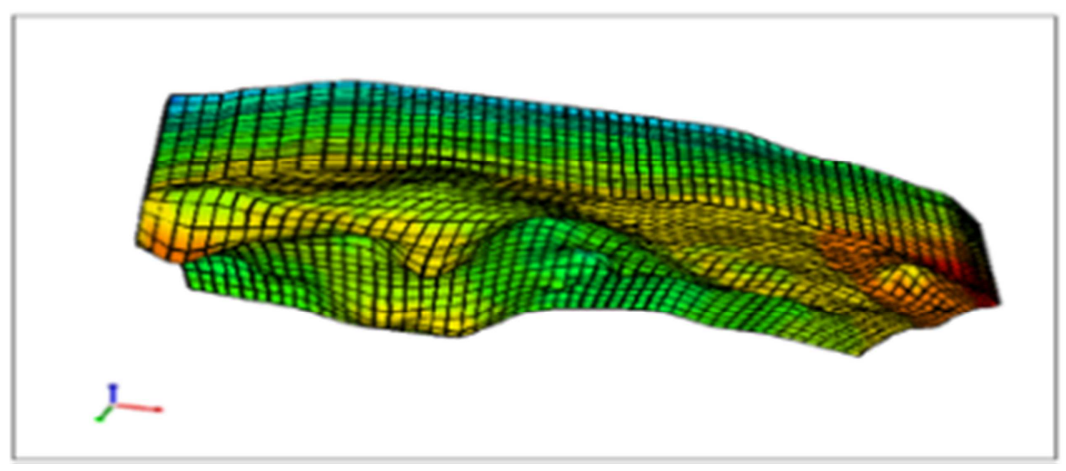

Figure 1. Black Oil model (CMG 2013 Simulator) Liaohe Oil Field.

The model is heterogeneous with pattern variation in permeability, porosity and well. The porosity range is 0.036 to 0.378 and the permeability range is between 1 to $689.8 \mathrm{mD}$. Oil and water are the active phases which are presented in this model. The original formation pressure is $17.5 \mathrm{MPa}$ and the bubble pressure is $16.13 \mathrm{MPa}$. At the reference pressure 17.5MPa, the initial oil and water density were $964.4 \mathrm{~kg} / \mathrm{m}^{3}$ and $1000 \mathrm{~kg} / \mathrm{m}^{3}$ at surface condition. The conventional injected water was composed of $3292.63 \mathrm{ppm}$ salinity. The oil area is $5.9 \mathrm{~km}^{2}$, the OOIP is $1227 \times 104 \mathrm{t}$, and the average 
effective thickness of the reservoir is $11.6 \mathrm{~m}$. The oil saturation is $65 \%$, and the water drive recovery is calibrated to $41.7 \%$.

Table 1. Data used in Start CMG (Sandstone Reservoir).

\begin{tabular}{lll}
\hline Number & Properties & Data \\
\hline 1 & Rock compressibility (CPOR) & $6.0^{*} 10-31 / \mathrm{MPa}$ \\
2 & Reservoir temperature & $71.5^{\circ} \mathrm{C}$ \\
3 & Injection temperature & $71.5^{\circ} \mathrm{C}$ \\
4 & Max injection pressure & $30000 \mathrm{KPa}$ \\
5 & Reference Depth & $2250 \mathrm{~m}$ \\
6 & WOC Depth & $1700 \mathrm{~m}$ \\
7 & BHP $(\mathrm{KPa})$ Production Well & 10000 \\
\hline
\end{tabular}

Table 2. Water-oil relative permeability.

\begin{tabular}{lll}
\hline Sw & Krw & Krow \\
\hline 0.3 & 0 & 1 \\
0.353 & 0.0015 & 0.8 \\
0.4 & 0.0033 & 0.608 \\
0.45 & 0.0063 & 0.42 \\
0.5 & 0.0104 & 0.283 \\
0.55 & 0.0156 & 0.191 \\
0.6 & 0.0264 & 0.131 \\
0.65 & 0.0416 & 0.08 \\
0.7 & 0.0576 & 0.051 \\
0.75 & 0.0758 & 0.028 \\
0.8 & 0.096 & 0.011 \\
0.85 & 0.1194 & 0 \\
\hline
\end{tabular}

\subsection{Water Flooding Design}

This part concerns the implementation of water flooding, a study on well pattern have been considered, include the optimization of injection and production parameters for water flooding.

\subsubsection{Well Pattern Analysis}

Five spot, seven spot and nine spot well pattern are designed in this research. Based on the highest oil recovery factor, the best well pattern was defined to maximize the injection and production rate. So, three pumping rate $(80 \mathrm{~m} 3 / \mathrm{d}$, $100 \mathrm{~m} 3 / \mathrm{d}$ and $120 \mathrm{~m} 3 / \mathrm{d}$ ) have been used to analyze and to define the best well pattern:

Table 3. Oil Recovery Factor and Injection Rate.

\begin{tabular}{|c|c|c|c|}
\hline Title & Qinj $=80 \mathrm{~m}^{3} / \mathrm{d}$ & Qinj $=100 \mathrm{~m}^{3} / \mathrm{d}$ & Qinj $=120 \mathrm{~m}^{3} / \mathrm{d}$ \\
\hline $\begin{array}{l}\text { Five Spot } \\
\text { Well Pattern }\end{array}$ & $25.45 \%$ ORF & $25.86 \% \mathrm{ORF}$ & $20.3 \%$ ORF \\
\hline $\begin{array}{l}\text { Seven Spot } \\
\text { Well Pattern }\end{array}$ & $26.4 \%$ ORF & $26.7 \%$ ORF & $26.3 \% \mathrm{ORF}$ \\
\hline $\begin{array}{l}\text { Nine Spot } \\
\text { Well Pattern }\end{array}$ & $24.29 \%$ ORF & $24.4 \%$ ORF & $23.1 \%$ ORF \\
\hline
\end{tabular}

The above table shows clearly that the best injection rate is $100 \mathrm{~m}^{3} / \mathrm{d}$. Then the suitable well pattern for this model is seven spot, about $26.7 \%$ of ORF can be obtained during water injection compare to five spot $(25.8 \%$ ORF) and nine spot (24.4\% ORF). The determination of flow rate of different wells for seven spot well pattern were defined by these equations:

$$
\begin{gathered}
\mathrm{Q}_{1}+1 / 2 \mathrm{Q}_{2}+1 / 2 \mathrm{Q}_{4}+1 / 4 \mathrm{Q}_{5}=\mathrm{I}_{1} \\
1 / 2 \mathrm{Q}_{2}+\mathrm{Q}_{3}+1 / 4 \mathrm{Q}_{5}+1 / 2 \mathrm{Q}_{6}=\mathrm{I}_{2} \\
1 / 2 \mathrm{Q}_{4}+\mathrm{Q} 7+1 / 4 \mathrm{Q}_{5}+1 / 2 \mathrm{Q}_{8}=\mathrm{I}_{3} \\
1 / 4 \mathrm{Q}_{5}+1 / 2 \mathrm{Q}_{6}+\mathrm{Q}_{9}+1 / 2 \mathrm{Q}_{8}=\mathrm{I}_{4}
\end{gathered}
$$

Table 4. Injection Parameters for water flooding.

\begin{tabular}{lllll}
\hline TItle & Well 1 & Well 2 & Well 3 & Well 4 \\
\hline $\begin{array}{l}\text { Injection Rate }\left(\mathrm{m}^{3} / \mathrm{d}\right) \\
\begin{array}{l}\text { Injection Pressure } \\
(\mathrm{Kpa})\end{array}\end{array}$ & 100 & 100 & 100 & 100 \\
\hline
\end{tabular}

Table 5. Injection and Production flow rate (Seven Spot).

\begin{tabular}{llll}
\hline Title & $\mathbf{I}=\mathbf{8 0} \mathbf{~ m}^{\mathbf{3}} / \mathbf{d}$ & $\mathbf{I}=\mathbf{1 0 0} \mathbf{~ m}^{\mathbf{3}} / \mathbf{d}$ & $\mathbf{I = 1 2 0} \mathbf{~ m}^{\mathbf{3}} / \mathbf{d}$ \\
\hline $\mathrm{Q}_{1}$ & 8.289777 & 10.36222 & 12.43467 \\
$\mathrm{Q}_{2}$ & 13.12859 & 16.41074 & 19.69289 \\
$\mathrm{Q}_{3}$ & 6.44043 & 8.050537 & 9.660645 \\
$\mathrm{Q}_{4}$ & 3.764896 & 4.70612 & 5.647344 \\
$\mathrm{Q}_{5}$ & 27.54056 & 34.4257 & 41.31084 \\
$\mathrm{Q}_{6}$ & 5.764592 & 7.20574 & 8.646888 \\
$\mathrm{Q}_{7}$ & 85.10773 & 106.3847 & 127.6616 \\
$\mathrm{Q}_{8}$ & 125.0062 & 143.2804 & 171.9365 \\
$\mathrm{Q}_{9}$ & 18.31923 & 20.183319 & 24.22 \\
$\mathrm{Q}_{10}$ & 4.082655 & 5.10334 & 6.123983 \\
$\mathrm{Q}_{11}$ & 7.772729 & 7.925646 & 9.510775 \\
$\mathrm{Q}_{12}$ & 7.907847 & 8.063423 & 9.676107 \\
$\mathrm{Q}_{13}$ & 4.85598 & 4.951514 & 5.941817 \\
$\mathrm{Q}_{14}$ & 15.65041 & 17.39795 & 20.87754 \\
$\mathrm{Q}_{15}$ & 1.732469 & 2.165587 & 2.598704 \\
$\mathrm{Q}_{16}$ & 2.706469 & 3.383086 & 4.059703 \\
\hline
\end{tabular}

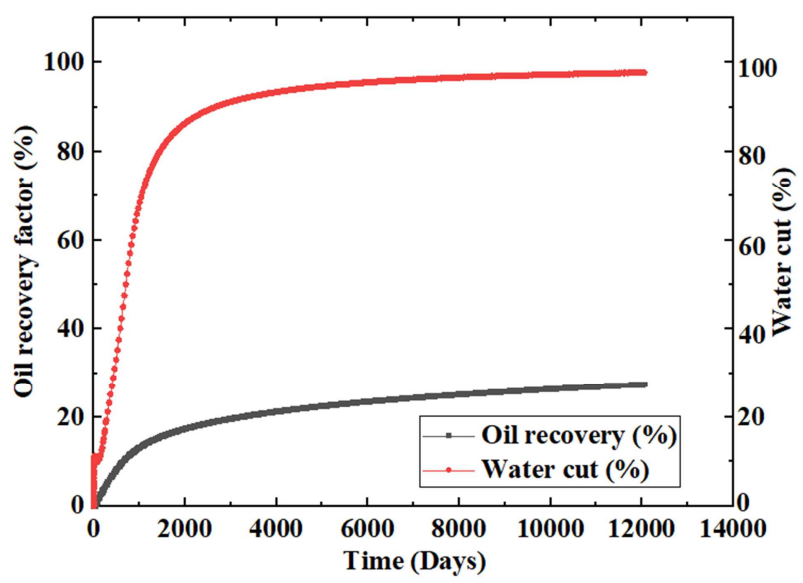

Figure 2. Oil Recovery Factor and Water Cut Curves (Seven Spot).

\subsubsection{Optimization of Injection and Production Parameters for Water Flooding}

Three parameters are optimized during water flooding application in this model: injection intensity, injection rate and liquid production. Therefore, based on the formation factor, $\mathrm{KH}$, of each production well, we get the production rate of each well according to the balance of injection and production. The injection intensity which is the ratio of water injection rate and net pay of each injection well, is used to optimize water injection rate for each injection well on the basis of the optimum well pattern. 
Table 6. Thickness Layers.

\begin{tabular}{|c|c|c|c|c|}
\hline Layer $n^{\circ}$ : & $\begin{array}{l}\text { Thickness } \\
\text { INJ. WELL } 1\end{array}$ & $\begin{array}{l}\text { Thickness } \\
\text { INJ. WELL } 2\end{array}$ & $\begin{array}{l}\text { Thickness } \\
\text { INJ. WELL } 3\end{array}$ & $\begin{array}{l}\text { Thickness } \\
\text { INJ. WELL } 4\end{array}$ \\
\hline 1 & 4.1764 & 2.4141 & 4.1163 & 3.1719 \\
\hline 4 & 2.4324 & 2.0094 & 2.464 & 1.6711 \\
\hline 7 & 5.0848 & 1.6204 & 3.8484 & 1.6877 \\
\hline 10 & 2.7581 & 1.5168 & 2.7583 & 1.668 \\
\hline 13 & 2.755 & 2.699 & 2.9552 & 1.9825 \\
\hline 16 & 2.7861 & 4.4182 & 2.8328 & 3.2296 \\
\hline 17 & 2.5914 & 3.5781 & 2.0662 & 2.9343 \\
\hline$H=\Sigma h(m)$ & 22.5842 & 18.256 & 21.0412 & 16.3451 \\
\hline
\end{tabular}

Table 7. Injection Intensity.

\begin{tabular}{lllll}
\hline Injection intensity & $\mathbf{I}_{\mathbf{1}}\left(\mathbf{m}^{\mathbf{3}} / \mathbf{d} . \mathbf{m}\right)$ & $\mathbf{I}_{\mathbf{2}}\left(\mathbf{m}^{\mathbf{3}} / \mathbf{d} . \mathbf{m}\right)$ & $\mathbf{I}_{\mathbf{3}}\left(\mathbf{m}^{\mathbf{3}} / \mathbf{d . m}\right)$ & \\
\hline 4 & 90.3368 & 73.024 & 84.1648 & \\
4.5 & 101.6289 & 82.152 & 94.6854 & \\
5 & 112.921 & 91.28 & 105.206 & 73.3804 \\
5.5 & 124.2131 & 100.408 & 115.7266 & 81.7255 \\
6 & 135.5052 & 109.536 & 126.2472 & 89.89805 \\
6.5 & 146.7973 & 118.664 & 136.7678 & 98.0706 \\
\hline
\end{tabular}

Table 8. Oil Recovery Factor and Injection intensity.

\begin{tabular}{|c|c|c|c|c|c|}
\hline Inj. Intensity & $4 \mathrm{~m}^{3} / \mathrm{d} . \mathrm{m}$ & $5 \mathrm{~m}^{3} / \mathrm{d} . \mathrm{m}$ & $5.5 \mathrm{~m}^{3} / \mathrm{d} . \mathrm{m}$ & $6 \mathrm{~m}^{3} / \mathrm{d} . \mathrm{m}$ & $6.5 \mathrm{~m}^{3} / \mathrm{d} . \mathrm{m}$ \\
\hline ORF & 26.4340 & 27.587 & 28.0375 & 28.169 & 27.9824 \\
\hline Water cut & $98 \%$ & $98 \%$ & $98 \%$ & $98 \%$ & $98 \%$ \\
\hline Time & 33 years & 33 years & 33 years & 33years & 33 years \\
\hline
\end{tabular}

Finally, a new parameter "M" $=\left[\frac{(K H)}{(K H)_{\max }}\right] /\left[\frac{\left(S_{a}-S_{o}\right)}{S_{o i}}\right]$, is introduced to design liquid production of each production well in order to optimize liquid production rate of production well in the actual oilfield. The initial saturation is equal to 0.65 , the dimensionless number "D" $=\mathrm{KH} /(\mathrm{KH}) \mathrm{max}$, and (Soi-So)/Soi, once obtained, we can get the new parameter "M" as a liquid rate (STL).

Table 9. Oil saturation.

\begin{tabular}{|c|c|c|c|c|c|c|c|c|}
\hline Soi & Layer 1 & Layer2 & Layer3 & Layer4 & Layer5 & Layer6 & Layer7 & Average So \\
\hline Sol & 0.55 & 0.53 & 0.52 & 0.51 & 0.49 & 0.51 & 0.49 & 0.51 \\
\hline So2 & 0.56 & 0.51 & 0.52 & 0.51 & 0.51 & 0.51 & 0.47 & 0.51 \\
\hline So3 & 0.49 & 0.51 & 0.51 & 0.51 & 0.49 & 0.49 & 0.46 & 0.50 \\
\hline So4 & 0.53 & 0.52 & 0.51 & 0.51 & 0.51 & 0.51 & 0.47 & 0.51 \\
\hline So5 & 0.52 & 0.50 & 0.52 & 0.50 & 0.52 & 0.49 & 0.4 & 0.50 \\
\hline So6 & 0.50 & 0.50 & 0.50 & 0.50 & 0.51 & 0.49 & 0.45 & 0.49 \\
\hline So7 & 0.49 & 0.42 & 0.49 & 0.49 & 0.48 & 0.48 & 0.46 & 0.48 \\
\hline So8 & 0.50 & 0.49 & 0.52 & 0.51 & 0.50 & 0.49 & 0.45 & 0.50 \\
\hline So 9 & 0.54 & 0.53 & 0.51 & 0.50 & 0.51 & 0.51 & 0.48 & 0.51 \\
\hline So10 & 0.55 & 0.51 & 0.51 & 0.48 & 0.49 & 0.49 & 0.46 & 0.50 \\
\hline So11 & 0.49 & 0.52 & 0.52 & 0.51 & 0.48 & 0.53 & 0.46 & 0.50 \\
\hline So12 & 0.54 & 0.56 & 0.56 & 0.55 & 0.55 & 0.57 & 0.47 & 0.54 \\
\hline So13 & 0.48 & 0.51 & 0.51 & 0.04 & 0.50 & 0.48 & 0.44 & 0.42 \\
\hline So14 & 0.50 & 0.52 & 0.53 & 0.52 & 0.51 & 0.51 & 0.49 & 0.51 \\
\hline So15 & 0.49 & 0.50 & 0.52 & 0.52 & 0.53 & 0.51 & 0.48 & 0.51 \\
\hline So16 & 0.51 & 0.49 & 0.52 & 0.52 & 0.50 & 0.52 & 0.47 & 0.51 \\
\hline
\end{tabular}

Table 10. Liquid flow Rate Optimization (STL).

\begin{tabular}{llll}
\hline \multicolumn{2}{l}{ PRODUCTION RATE OPTIMIZATION } & & New parameter Mi=Di/Roi \\
\hline \multicolumn{2}{l}{ Dimensionless Number $\mathbf{D}=(\mathbf{K h}) \mathbf{i} /(\mathbf{K h}) \mathbf{m a x}$} & $\mathrm{M} 1$ & 34.80931 \\
\hline $\mathrm{D}_{1}$ & 0.313868702 & $\mathrm{M} 2$ & 21.34835 \\
$\mathrm{D}_{2}$ & 0.220785409 & $\mathrm{M} 3$ & 12.19756 \\
$\mathrm{D}_{3}$ & 0.147882524 & $\mathrm{M} 4$ & 8.840741 \\
$\mathrm{D}_{4}$ & 0.107184611 & $\mathrm{M} 5$ & 59.20448 \\
$\mathrm{D}_{5}$ & 0.717791596 & $\mathrm{M} 6$ & 7.04343 \\
$\mathrm{D}_{6}$ & 0.069242424 & $\mathrm{M} 7$ & 66.05532 \\
$\mathrm{D}_{7}$ & 0.630405749 & $\mathrm{M} 8$ & 118.4903 \\
$\mathrm{D}_{8}$ & 1 & & \\
\hline
\end{tabular}




\begin{tabular}{llll}
\hline \multicolumn{2}{l}{ PRODUCTION RATE OPTIMIZATION } & & New parameter Mi=Di/Roi \\
\hline \multicolumn{2}{l}{ Dimensionless Number $\mathbf{D}=(\mathbf{K h}) \mathbf{i}(\mathbf{K h}) \mathbf{m a x}$} & $\mathrm{M} 9$ & 28.437 \\
\hline $\mathrm{D}_{9}$ & 0.242522895 & $\mathrm{M} 10$ & 14.73164 \\
$\mathrm{D}_{10}$ & 0.132832251 & $\mathrm{M} 11$ & 17.82535 \\
$\mathrm{D}_{11}$ & 0.144211278 & $\mathrm{M} 12$ & 35.15971 \\
$\mathrm{D}_{12}$ & 0.28445035 & $\mathrm{M} 13$ & 5.072448 \\
$\mathrm{D}_{13}$ & 0.041037301 & $\mathrm{M} 14$ & 23.74156 \\
$\mathrm{D}_{14}$ & 0.19415184 & $\mathrm{M} 15$ & 6.399751 \\
$\mathrm{D}_{15}$ & 0.052907473 & $\mathrm{M} 16$ & 10.002 \\
$\mathrm{D}_{16}$ & 0.082687682 & & \\
\hline
\end{tabular}

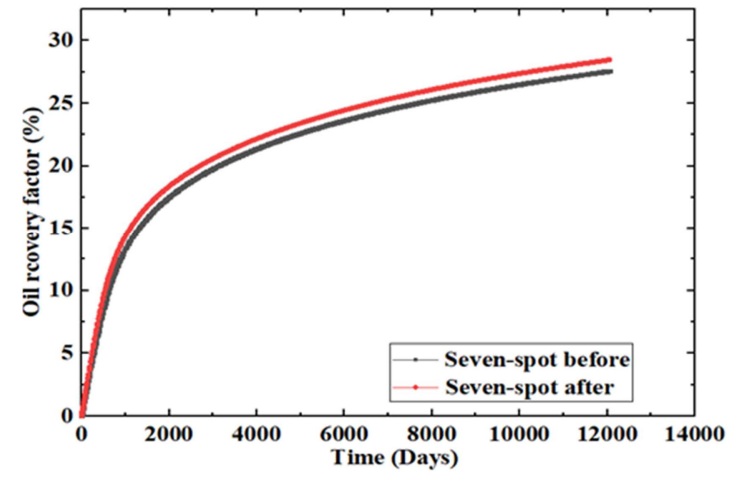

Figure 3. Oil Recovery Factor Curves before and after optimization of Water flooding.

\subsection{Gel Flooding Design}

Initially, water flooding was applied, an excessive production of water has been observed during the production stage. Due to serious water channeling between injection wells and production wells and also the heterogeneity of the reservoir, an EOR method, gel flooding, is employed to decrease water mobility in channeling path and increase sweep efficiency of injection liquids after water flooding. Therefore, based on the value of injection rate and liquid production rate optimized during water flooding, gel flooding is designed.

\subsubsection{Laboratory Experiment: Gel Selection and Properties}

Two Cross linkers were analyzed and compared in the laboratory, organic chromium gel phenolic transfer system and phenolic gel transfer system. Therefore, the first gel system was selected to be used in this research because of the low price and gelation time compare to the second one.

The solution gel used in this model is a mixture of polymer and cross linking agent, the properties of these two substances are described in details below:

\section{i. Polymer Molecular Weight}

The average permeability is about $450-700 \mathrm{mD}$, the molecular weight can be chosen between 2000-2500 $\times 104$.

Table 11. The relationship between core permeability and polymer molecular weight.

\begin{tabular}{ll}
\hline Permeability $\times \mathbf{1 0 - 3} \boldsymbol{\mu m} \mathbf{2}$ & Polymer molecular weight $\times \mathbf{1 0 4}$ \\
\hline $200-300$ & $500-820$ \\
$300-350$ & $820-1100$ \\
$350-450$ & $1100-1800$ \\
$450-700$ & $1800-2800$ \\
\hline
\end{tabular}

\section{ii. Polymer Concentration}

a. When the mass concentration of polymer is less than $0.1 \%$, the viscosity of gel is lower than $500 \mathrm{mPa} \cdot \mathrm{s}$.

b. When the mass concentration of polymer is more than $0.1 \%$, the viscosity of gel is larger than $1000 \mathrm{mPa} \cdot \mathrm{s}$.

c. When the mass concentration of polymer is more than $0.2 \%$, the viscosity of gel is basically stable. Therefore, this concentration $0.2 \%$ is chosen.

The gelation time is about from 2 to 4 days.

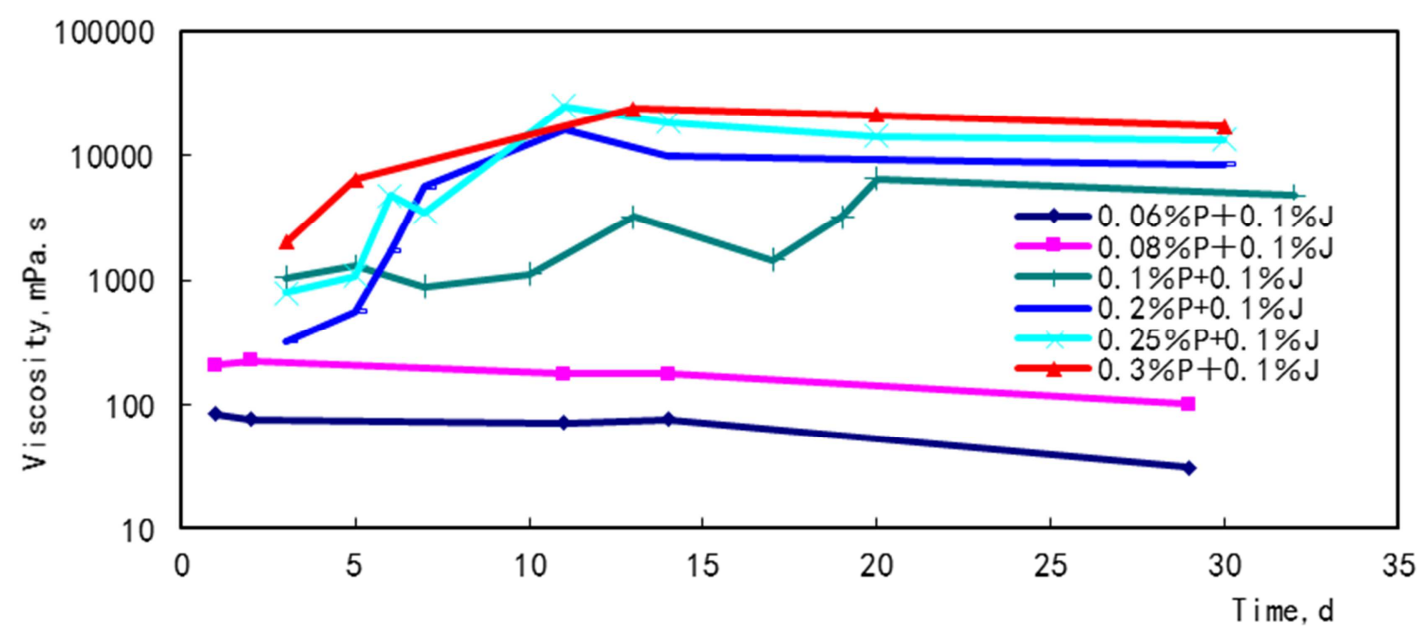

Figure 4. Polymer concentration. 


\section{iii. CrossLinking Agent}

The slug of gel floding: $0.2 \%$ Polymer $+0.1 \%$ Crosslinking agent.

Table 12. Gel Concentration.

\begin{tabular}{ll}
\hline Title & Gel concentration \\
\hline Components & $0.2 \%$ Polymer $+0.1 \%$ Crosslinking agent \\
Gelation time(d) & $1 \sim 3$ \\
Gel viscosity(mPa.s) & $8000-12000$ \\
Blocking Percentage(\%) & $>80$ \\
Price(RMB/m3) & 50 \\
\hline
\end{tabular}

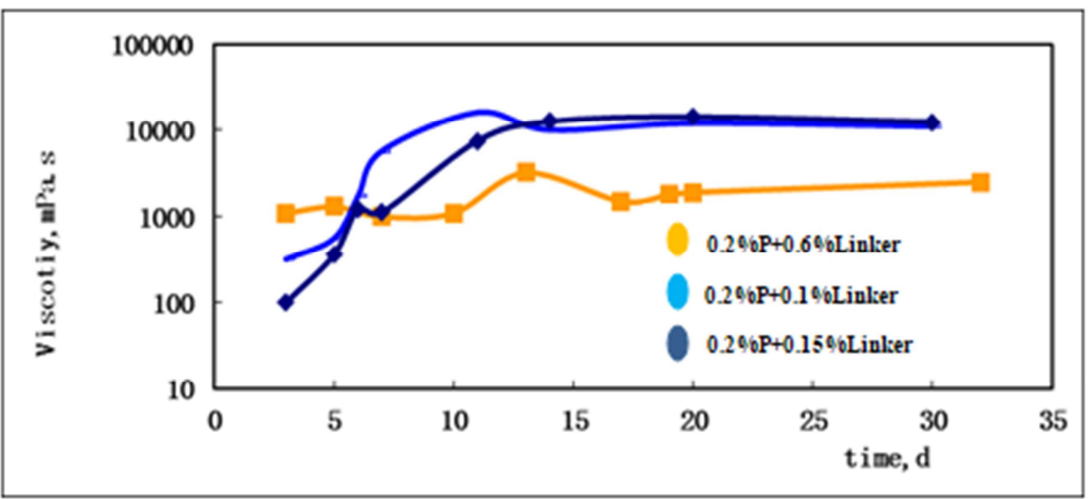

Figure 5. Gel concentration.

\subsubsection{Injection and Production Parameters for Gel Flooding}

The oil recovery factor can be maximized in the actual oil field based on optimized injection design of gel flooding, especially injection rate, gel concentration and injection time gel.

\section{i. Injection Rate}

The optimized injection rate used during gel flooding treatment improved the oil recovery up to $34 \%$ compare to $32 \%$ obtained before optimization of gel injection rate.

Table 13. Injection rate for gel flooding within $0.2 \%$ gel concentration before and after optimization.

\begin{tabular}{|c|c|c|c|c|c|}
\hline TITLE & Well 1 & Well 2 & Well 3 & Well 4 & ORF \\
\hline Injection Rate $\left(\mathrm{m}^{3} / \mathrm{d}\right)$ before Optimization & 100 & 100 & 100 & 100 & $32 \%$ \\
\hline Injection Rate $\left(\mathrm{m}^{3} / \mathrm{d}\right)$ After Optimization & 135.5052 & 109.536 & 126.2472 & 98.0706 & $34 \%$ \\
\hline
\end{tabular}

\section{ii. Gel Concentration}

During gel design, the initial concentration of gel used was $0.2 \%$. So, after using different concentration from 0.2 to $0.6 \%$ and according to the simulation results showed in the table below, the oil recovery factor increased lightly. Economically for the reason of price and gel volume, $0.2 \%$ remains the best gel concentration. Others gel concentration are not taken into account or neglected because of the slow change of ORF.

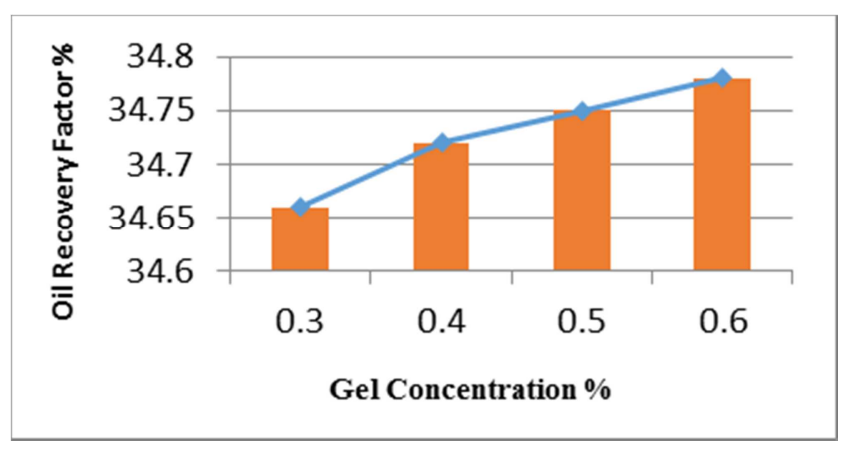

Figure 6. Gel concentration.
Table 14. Gel Concentration.

\begin{tabular}{llllll}
\hline Gel Conc. \% & $\mathbf{0 . 2}$ & $\mathbf{0 . 3}$ & $\mathbf{0 . 4}$ & $\mathbf{0 . 5}$ & $\mathbf{0 . 6}$ \\
\hline WATER & 0.997 & 0.9955 & 0.994 & 0.9925 & 0.991 \\
LINKER & 0.001 & 0.0015 & 0.002 & 0.0025 & 0.003 \\
XANTHAN & 0.002 & 0.003 & 0.004 & 0.005 & 0.006 \\
ORF (\%) & 34 & 34.6 & 34.7 & 34.7 & 34.7 \\
\hline
\end{tabular}

\section{iii. Injection time}

A range of injection time from 1 to 3 years were used to evaluate the effect of gel injection in oil production for the actual oil field. The table below showed the change of oil recovery factor respect to time of gel injected.

Table 15. ORF vs Injection Time.

\begin{tabular}{llllll}
\hline YEAR & $\mathbf{1}$ & $\mathbf{1 . 5}$ & $\mathbf{2}$ & $\mathbf{2 . 5}$ & $\mathbf{3}$ \\
\hline $\mathrm{ORF} \%$ & 34.35 & 34.64 & 34.77 & 34.83 & 34.89 \\
\hline
\end{tabular}

It obvious from the above table that the change of gel injection time affect oil production but from 2 to 3 years the ORF changes lightly. So, two years of gel injection has been considered as the best injection time. 


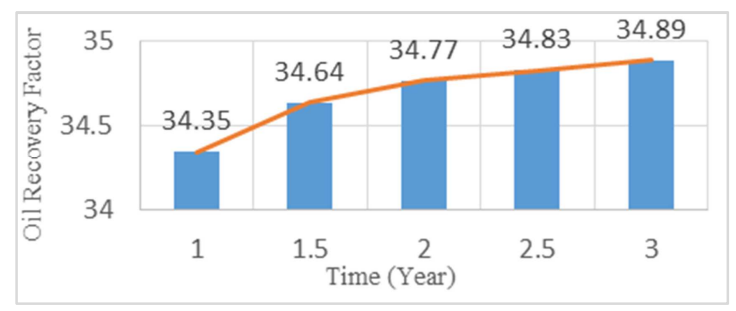

Figure 7. Gel Volume.

\section{Results and Discussion}

The numerical simulation results from the implementation of water flooding to gel flooding show that:

a. The oil recovery factor after optimization of gel flooding increases up to $34.7 \%$ compare to $28 \%$ of water injection.

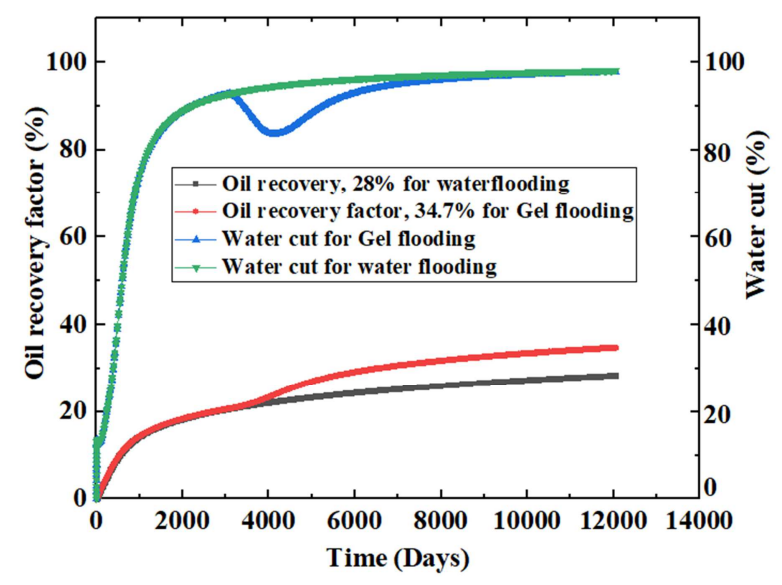

Figure 8. Water flooding vs Gel flooding.

b. The water saturation distribution for gel flooding (figure 9.b) is almost circle compare to water flooding (figure 9.a). Below, an example of the first layer is illustrated to show the effect of gel treatment and change of water fingering.

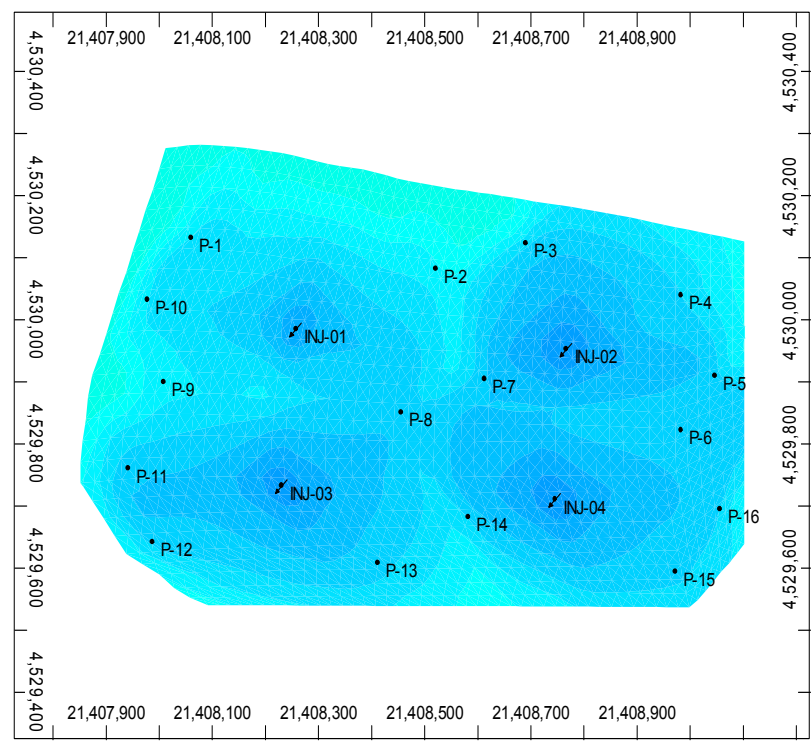

(a)

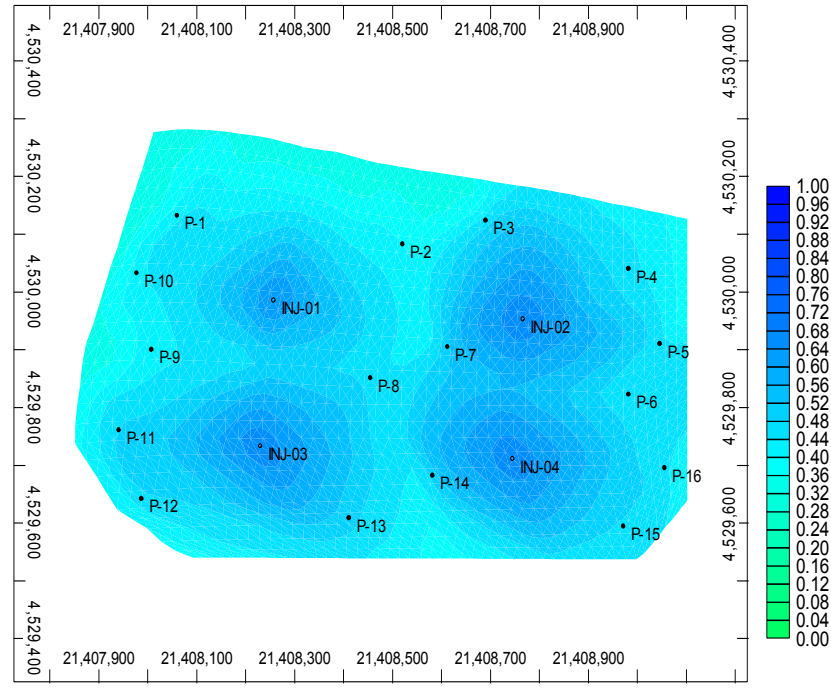

(b)

Figure 9. Water Saturation.

c. The average pressure during gel injection increased up to $17320 \mathrm{KPa}$ compare to 17222 to KPa of water flooding.

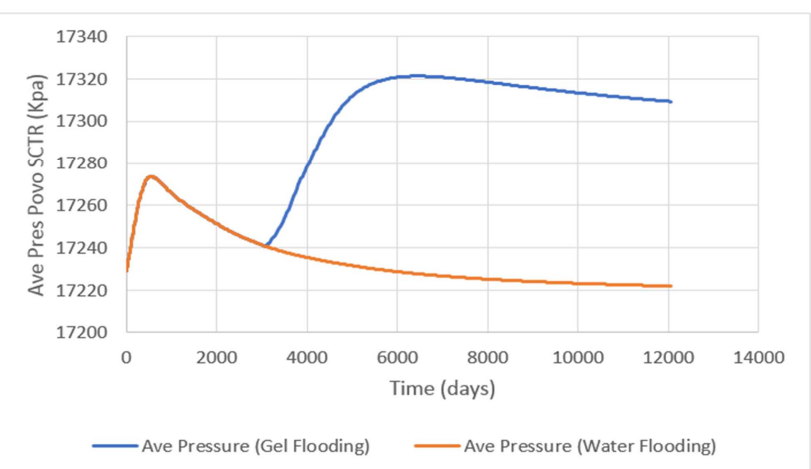

Figure 10. Average pressure Curves.

d. The Oil Production Cumulative after gel injection increased up to 659361 (m3) compare to 522468 (m3) of water flooding.

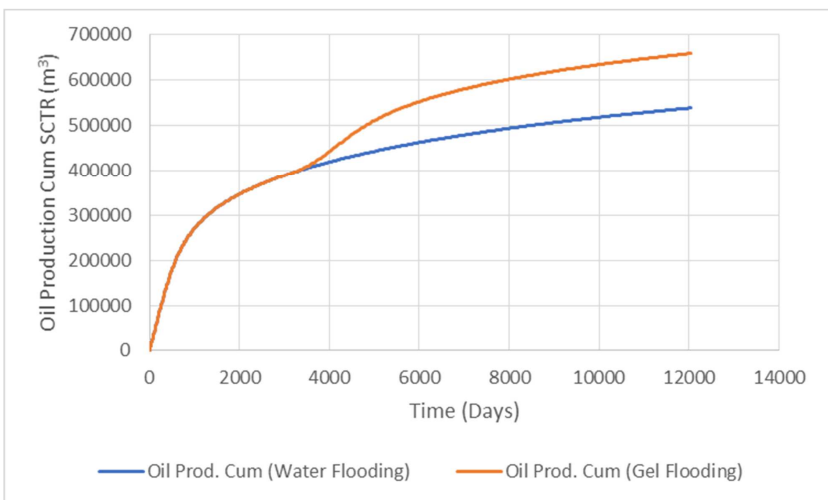

Figure 11. Oil Production Cumulative Curves. 
Table 16. Simulation Results: Water flooding vs Gel flooding.

\begin{tabular}{lll}
\hline TITLE & WATER FLOODING & GEL FLOODING \\
\hline Well Design & Seven spot & Seven spot \\
Oil Recovery Factor (ORF) & $26.7 \%$ & $32 \%$ \\
ORF after Optimization & $28 \%$ & $34.7 \%$ \\
Water Cut & $98 \%$ & $84 \%$ \\
Flow Line & No uniform & Circle \\
Parameters & Injection Intensity: $6 \mathrm{~m}^{3} / \mathrm{d} \cdot \mathrm{m}(28.1 \%$ ORF $)$. & Gel Concentration: $0.2 \%(34.75 \%$ ORF). Injection Time: 2 years. \\
\hline
\end{tabular}

\section{Conclusions}

A reservoir model has been established in this work to evaluate Gel Flooding treatment in Hai 1 block of Liaohe oil field. The aim was to analyze the improvement of oil recovery by applying gel flooding in that block as said in the introduction. Three well patterns such as five point, seven point and nine point, were developed for water flooding and gel flooding. Based on the reservoir parameters and fluid properties of Hai 1 block, include simulation, well pattern, injection rate and liquid production rate have been designed and optimized in this research.

The following conclusions can be drawn from this work: (i) Seven spot is the best well pattern and it is more accurate for this model with $26.7 \%$ of oil recovery factor compare to five spot $(25.8 \%$ ORF) and nine spot (24.4\% ORF); (ii) During water flooding application, the optimization of liquid production rate improved the oil recovery up to $28.4 \%$ compare to $26.7 \%$ obtained before optimization of injection and production parameters when water cut equals to $98 \%$; (iii) After two years of gel injection, it has been observed that excessive production of water decreased from 98 to $84 \%$ and the ultimate oil recovery (ORF) for the entire field increased up to $34.5 \%$ compare to $28 \%$ ORF of water flooding.

In the other hand, the parameters that affect the oil production observed in this work, have demonstrated that gel flooding improved significantly the oil recovery and lower water production by plugging higher permeability zone and increasing sweep efficiency in hail block.

\section{References}

[1] Sydansk, R. D. (1988). A new conformance-Improvement-Treatment Chromium (III) Gel Technology. In SPE/DOE Enhanced Oil Recovery Symposium. Tulsa, Oklahoma: SPE.

[2] CenkTemizel, Dike Putra, Zumra Peksaglam, Onur Susuz, Karthik Balaji, Anuj Suhag, Rahul Ranjith, and Ming Zhang. Production Optimization under Injection of Biopolymer, Synthetic Polymer and Gels in a Heterogeneous Reservoir. 2016, Society of Petroleum Engineers.

[3] Alpay, O.A, 1972, A practical approach to defining reservoir heterogeneity. Journal of PetroleumTechnology, 24, pp 841-848.

[4] Satter, G. Iqbal \& J. Buchwalter, 2008, "Practical Enhanced Reservoir Engineering”, Penn Well Corporation, Oklahoma, pp.62-72.
[5] T. Khamees, R. E. Flori, and M. Wei, Missouri University of Science \& Technology, 2017,SPE-185716-MS, Simulation Study of In-Depth Gel Treatment in Heterogeneous Reservoirs with Sensitivity Analyses.

[6] Yanlai Li, Yanchun Su, Kuiqian Ma, Qizheng Li, Xiaofei Jia, CNOOC Ltd.-Tianjin, 2011, SPE 146617 Gel Flooding Pilot Test and Evaluation Method Studies to Control Water Channeling in Conventional Heavy Oil Reservoir of Bohai Bay.

[7] Aldhaheri, Munqith Naeem Rashak, "Screening guidelines and data analysis for the application of in-situ polymer gels for injection well conformance improvement" (2017). Doctoral Dissertations. 2555.

[8] Bai, B., et al., Case Study on Prefromed Particle Gel for In-Depth Fluid Diversion. 2008, Society of Petroleum Engineers.

[9] Han, M., Alshehri, A. J., Krinis, D., \& Lyngra, S. (2014, April 21). State-of-the-Art of In Depth Fluid Diversion Technology: Enhancing Reservoir Oil Recovery by Gel Treatments. Society of Petroleum Engineers.

[10] Lantz, M. and G. Muniz, Conformance Improvement Using Polymer Gels: A Case Study Approach. 2014, Society of Petroleum Engineers.

[11] Liao, Jingyi, "Gel treatment field application survey for water shut off in production wells" (2014). Masters Theses. Paper 7333.

[12] Wang, H., Guo, W., \& Jiang, H. (2001, January 1). Study and Application of Weak Gel System Prepared by Complex Polymer Used for Depth Profile Modification. Society of Petroleum Engineers. doi:10.2118/65379-MS.

[13] Zhao G, Dai C, Zhao M (2014) Investigation of the Profile Control Mechanisms of Dispersed Particle Gel).

[14] Alvarado, V. and E. Manrique, Enhanced Oil Recovery - Field Planning and Development Strategies. 2010, Elsevier.

[15] Green, D. W., \& Willhite, G. P. (1998). Enhanced oil recovery. Richardson, Tex.: Henry L. Doherty Memorial Fund of AIME, Society of Petroleum Engineers.

[16] Sydansk, R. D., and Romero-Zeron, L. (2011). Reservoir conformance improvement. Society of Petroleum Engineers.

[17] Azari, M., \& Soliman, M. (1996, January 1). Review of Reservoir Engineering Aspects of Conformance Control Technology. Society of Petroleum Engineers. http://dx.doi.org/10.2118/35171-MS.

[18] Seright, R. S., Lane, R. H., \& Sydansk, R. D. (2001, January 1). A Strategy for Attacking Excess Water Production. Society of Petroleum Engineers. http://dx.doi.org/10.2118/70067-MS.

[19] Smith, D. and Ott, B. 2006b. Conformance Engineering: A Comprehensive Review. Part 2: Connecting the Problem to an Effective Solution. World Oil, June, p 95-98. 